\title{
Texture Hardening Observed in Mg-Zn-Nd Alloy Processed by Equal-Channel Angular Pressing (ECAP)
}

\author{
Jitka Stráská $^{1, *}$, Peter Minárik ${ }^{1} \mathbb{D}$, Stanislav Šašek ${ }^{1}$, Jozef Veselý ${ }^{1}$, Jan Bohlen ${ }^{2}$, Robert Král ${ }^{1} \mathbb{D}$ \\ and Jiří Kubásek ${ }^{3}(\mathbb{D}$ \\ 1 Department of Physics of Materials, Charles University, 12116 Prague, Czech Republic; \\ peter.minarik@mff.cuni.cz (P.M.); sasekstanislav@seznam.cz (S.Š.); vesely@gjh.sk (J.V.); \\ rkral@met.mff.cuni.cz (R.K.) \\ 2 Helmholtz-Zentrum Geesthacht, Magnesium Innovation Centre, 21502 Geesthacht, Germany; \\ jan.bohlen@hzg.de \\ 3 Department of Metals and Corrosion Engineering, University of Chemistry and Technology, \\ 16628 Prague, Czech Republic; Kubasek.jiri@gmail.com \\ * Correspondence: straska.jitka@gmail.com; Tel.: +420-95155-1613
}

Received: 27 November 2019; Accepted: 17 December 2019; Published: 24 December 2019

\begin{abstract}
The addition of $\mathrm{Nd}$ significantly improves the mechanical properties of magnesium alloys. However, only limited amounts of $\mathrm{Nd}$ or other rare earth (RE) elements should be used due to their high price. In this study, a low-alloyed Mg- $1 \% \mathrm{Zn}-1 \% \mathrm{Nd}$ (ZN11) alloy was designed and processed by hot extrusion and subsequent equal-channel angular pressing (ECAP) in order to achieve a very fine-grained condition with enhanced strength. The microstructure, texture, and mechanical properties were thoroughly studied. The microstructure after 8 passes through ECAP was homogeneous and characterized by an average grain size of $1.5 \mu \mathrm{m}$. A large number of tiny secondary phase precipitates were identified as ordered Guinier-Preston (GP) zones. Detailed analysis of the Schmid factors revealed the effect of the texture on deformation mechanisms. ECAP processing more than doubled the achieved yield compression strength (YCS) of the ZN11 alloy. Significant strengthening by ECAP is caused by grain refinement and the formation of ordered Guinier-Preston zones and particles of a secondary $\gamma$-phase.
\end{abstract}

Keywords: magnesium; severe plastic deformation; equal-channel angular pressing; microstructure; deformation tests; texture; schmid factor

\section{Introduction}

Magnesium materials usually have very low density and high specific strength. The intended applications of lightweight magnesium products are primarily in the automotive or aerospace industries [1]. The addition of alloying elements determines the fundamental properties of the alloys. In our study, we focused on $\mathrm{Mg}-\mathrm{RE}-\mathrm{Zn}$ alloys, namely a $\mathrm{Mg}-\mathrm{Nd}-\mathrm{Zn}$ alloy.

$\mathrm{Zn}$ is often utilized as an alloying element in magnesium alloys, because it can improve mechanical properties of $\mathrm{Mg}$ alloys by solid solution strengthening [2]. However, for practical purposes in structural parts, the strength and fracture toughness of binary $\mathrm{Mg}-\mathrm{Zn}$ alloys should be further improved, including at elevated temperatures [3]. It has been reported that rare earth (RE) elements can improve the tensile properties of $\mathrm{Mg}$ alloys both at room temperature and at elevated temperatures [4]. Even a low additional content of $\mathrm{Nd}$ can result in significant increases in hardness and yield strength of ternary $\mathrm{Mg}-\mathrm{Zn}-\mathrm{Nd}$ alloys after adequate thermal treatment [3]. The increase in hardness and strength is caused 
by the formation of plate-shaped Guinier-Preston (GP) zones and $\mathrm{Mg}_{3} \mathrm{Nd}$ phases [5]. The addition of $\mathrm{Zn}$ to $\mathrm{Mg}-\mathrm{RE}$ alloys decreases the required concentrations of RE additions for achieving mechanical properties similar to binary Mg-RE alloys. This is beneficial for the adoption of RE-containing Mg alloys in industrial applications (such as the automotive industry) since RE elements are relatively expensive [6]. Yang et al. studied the mechanical properties and microstructure of $\mathrm{Mg}-4.5 \mathrm{Zn}-x \mathrm{Nd}$ ( $x=0,1$, and $2 \mathrm{wt} . \%$ ) alloys, and the best mechanical properties were obtained in the alloy with smaller amounts of $\mathrm{Nd}$ (1 wt.\% of $\mathrm{Nd}$ ) [3]. We also considered Nie's thorough review in which he showed that increased content of $\mathrm{Zn}(>1.3 \mathrm{wt} . \%)$ in $\mathrm{Mg}-\mathrm{Nd}-\mathrm{Zn}$ alloys can cause detrimental effects on the possible precipitation hardening [7]. Therefore, the presented study focuses on low-alloyed magnesium alloy ZN11 (Mg-1 wt.\% Zn-1 wt.\% Nd).

Solid solution strengthening and precipitation hardening are very effective and important in all magnesium alloys. Additionally, grain boundary strengthening is capable of further improving mechanical properties. Severe plastic deformation techniques are very useful methods for preparing ultrafine-grained materials.

Equal-channel angular pressing (ECAP) is a severe plastic deformation (SPD) technique based on repetitive simple shear. The facility for ECAP is comparatively simple and it is easily scaled-up to produce materials with reasonably large dimensions [8]. Various magnesium alloys were successfully prepared by ECAP, and the obtained microstructures were ultrafine-grained or even nanostructured (depending on the ECAP process parameters, especially ECAP temperature, and on the processed material — the amount and type of alloying elements and previous thermo-mechanical treatments) [9-11]. Zhao et al. investigated $\mathrm{Mg}-3.0 \mathrm{Nd}-0.4 \mathrm{Zn}-0.5 \mathrm{Zr}$ alloy, prepared by integrated extrusion and ECAP, and an ultrafine-grained microstructure with an average grain size of $\sim 0.5 \mu \mathrm{m}$ was obtained [12]. Zhang et al. prepared a Mg-2.0Nd-0.2 wt.\% Zn alloy by friction stir processing, which resulted in grain refinement to $\sim 2 \mu \mathrm{m}$ [13]. Analogous grain refinement to the grain size of $\sim 2 \mu \mathrm{m}$ was achieved by Dvorský et al. in a similar Mg-3.0Nd-0.5Zn alloy, processed by hot extrusion only [14].

Properties of low-alloyed $\mathrm{Mg}-\mathrm{Nd}-\mathrm{Zn}$ alloys processed by the SPD method have not yet been properly studied.

In this contribution, the low-alloyed magnesium alloy ZN11-prepared by extrusion and ECAP - was investigated with a focus on microstructure, texture, secondary phases, and mechanical properties.

\section{Materials and Methods}

The experimental magnesium alloy ZN11 (Mg-1 wt.\% Zn-1 wt.\% Nd) was cast in Helmholtz-Zentrum Geesthacht, Germany, and extruded at $400{ }^{\circ} \mathrm{C}$, with an extrusion ratio of 30 and a crosshead speed of $1 \mathrm{~mm} / \mathrm{s}$. Bars with the cross-section $10 \times 10 \mathrm{~mm}^{2}$ were machined from the extruded rod. Samples with a length of $10 \mathrm{~cm}$ were processed by ECAP, with the die having the inner angle of $90^{\circ}$, following route $\mathrm{B}_{\mathrm{C}}$ [15]. The processing temperatures and pressing speeds for ZN11 after extrusion are shown in Table 1. Each pass of the ECAP process was performed at the lowest possible temperature, because deformation temperature has a very strong effect on the resulting microstructure and mechanical properties, as was shown in the AX41 magnesium alloy by Krajñák et al. in [16] and for other materials [17-22]. Note that further decrease of the processing temperature would lead to occurrence of cracking and billet segmentation. Four conditions were investigated in this study: as-extruded (EX) condition, and conditions after one pass through ECAP (1P), four passes (4P), and eight passes $(8 \mathrm{P})$.

Table 1. ECAP (Equal-Channel Angular Pressing) procedure parameters of the investigated alloy.

\begin{tabular}{ccccccccc}
\hline ECAP Pass Number & $\mathbf{1}$ & $\mathbf{2}$ & $\mathbf{3}$ & $\mathbf{4}$ & $\mathbf{5}$ & $\mathbf{6}$ & $\mathbf{7}$ & $\mathbf{8}$ \\
\hline Processing Temperature $\left({ }^{\circ} \mathrm{C}\right)$ & 340 & 330 & 320 & 310 & 300 & 290 & 280 & 280 \\
Pressing Speed $(\mathrm{mm} / \mathrm{min})$ & 5 & 7 & 10 & 10 & 10 & 10 & 10 & 10 \\
\hline
\end{tabular}


The microstructure of all samples was investigated by scanning and transmission electron microscopy (SEM, TEM). An SEM Zeiss Auriga Compact (Zeiss, Oberkochen, Germany), equipped with an EDAX electron backscattered diffraction (EBSD) camera (EDAX Inc., Mahwah, NJ, USA), was used for the investigation of the grain structure. EBSD analysis was performed with a scan size of $400 \times 400 \mu \mathrm{m}^{2}$ and a step size of $0.4 \mu \mathrm{m}$ in the case of the extruded sample, and a scan size of $100 \times 100 \mu \mathrm{m}$ and step size of $0.1 \mu \mathrm{m}$ in the case of the samples processed by ECAP. The raw data were partially cleaned in OIM TSL software (EDAX Inc., Mahwah, NJ, USA) using one step of confidence index $(\mathrm{CI})$ standardization and one step of grain dilatation. Note that only points with $\mathrm{CI}>0.1$ were used for calculations. Analysis regarding occurrence of twinning in the pre-deformed sample was performed by in-built feature in OIM TSL software. Only one type of twin, tension twin $\{10 \overline{1} 2\}\langle 10 \overline{1} 1\rangle$ (the misorientation angle between the matrix and the twin-86.4 around $\langle a\rangle$-axis), was observed. TEM JEOL 2200FS (JEOL USA Inc., Peabody, MA, USA), operating at $200 \mathrm{kV}$, was used for secondary phase analysis. Samples for EBSD measurements and thin TEM discs were mechanically prepared and subsequently ion-polished using a Leica EM RES102 (Leica Microsystems GmbH, Wien, Austria). The texture of the initial as-extruded condition was investigated by an X-ray PANalytical XPert MRD diffractometer (XRD) (Malvern Panalytical Ltd, Grovewood Road Malvern, UK). $\mathrm{Cu}_{\mathrm{K}}$ radiation and polycapillaries in the primary beam were employed during the measurements. The full pole figures were calculated using MTEX software (TU Chemnitz, Chemnitz, Germany) [23].

Mechanical properties were studied using the Vickers microhardness measurement and compression and tensile deformation tests. Microhardness measurements were performed by a Qness Q10 device (Qness GmbH, Colling, Austria) with a load of $0.5 \mathrm{~kg}$ (HV 0.5) for $10 \mathrm{~s}$. Microhardness was measured on a cross-section plane. More than 100 experimental points (indents) were evaluated for each specimen. Compression and tensile deformation tests were performed using a universal testing device (Instron 5882, Instron, Coronation Road, Buckinghamshire, UK). Compression tests were performed on cuboid specimens with the aspect ratio of 2:3 $\left(4 \times 4 \times 6 \mathrm{~mm}^{3}\right)$. The samples were machined with the deformation axis parallel to the extrusion direction (ED), normal direction (ND) and transverse direction (TD), see Figure 1. Note that compression tests along ND and TD were performed only for the 8P sample. Tensile deformation tests were performed only for the 8P sample along ED. Bone-shaped flat samples with a rectangular cross-section of $4 \times 1.4 \mathrm{~mm}^{2}$ and a gauge length of $10 \mathrm{~mm}$ were machined. At least three samples for each combination of deformation axis, deformation direction and materials condition were tested. Finally, the true stress-strain curves were calculated from the engineering stress-strain curves (see [24], for example).

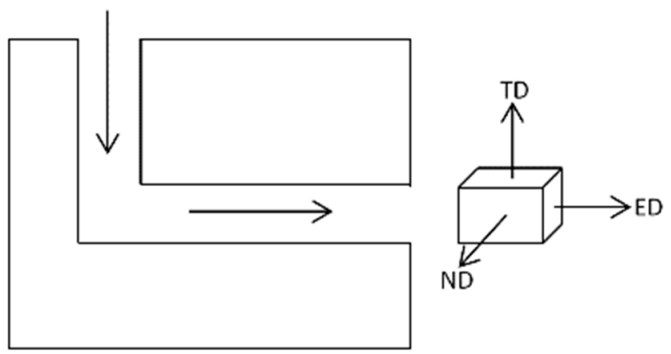

Figure 1. Mutual orientation of the equal-channel angular pressing (ECAP) die and the billet.

\section{Results}

\subsection{As-Extruded Condition}

The initial, as-extruded, microstructure of the investigated alloy was studied by EBSD, TEM, and XRD. Figure 2a shows the EBSD orientation map revealing the grain structure of the material. It is clear that extrusion resulted in a significant grain refinement, and the formation of a homogeneous, fully recrystallized microstructure. The grain size-determined as the average value weighted by the area fraction-was $\sim 11 \mu \mathrm{m}$. 
The presence of small secondary phase particles is clearly seen in the TEM micrograph in Figure $2 b$. Many grain boundaries are decorated by small particles in a necklace-like formation. Local chemical analysis and selected area electron diffraction confirmed that the particles are stable $\gamma$-phase $\mathrm{Mg}_{3}$ $(\mathrm{Nd}, \mathrm{Zn})$, face-centered cubic (FCC) structure, $F m \overline{3} m$, with $a=0.70 \mathrm{~nm}$ [7]. The size of the $\gamma$-phase particles varied from $\sim 100 \mathrm{~nm}$ to $1 \mu \mathrm{m}$. In addition, Figure $2 \mathrm{~b}$ discloses that the grain interiors are almost strain-free.

XRD measurement was performed to acquire information about the texture formation during the extrusion. Extrusion of magnesium alloys usually leads to the formation of the typical (1010) fiber texture, which is often strong (explained theoretically by Mayama et al. [25]). However, Figure 3 shows that the texture observed in the investigated ZN11 alloy was completely different. This kind of texture has already been observed in $\mathrm{Mg}-\mathrm{RE}$ alloys after extrusion, and is referred to as "rare earth texture" [26]. In the investigated sample, this texture component is weak, and is represented by grains which have their c-axis tilted from ED by approximately $45^{\circ}$.
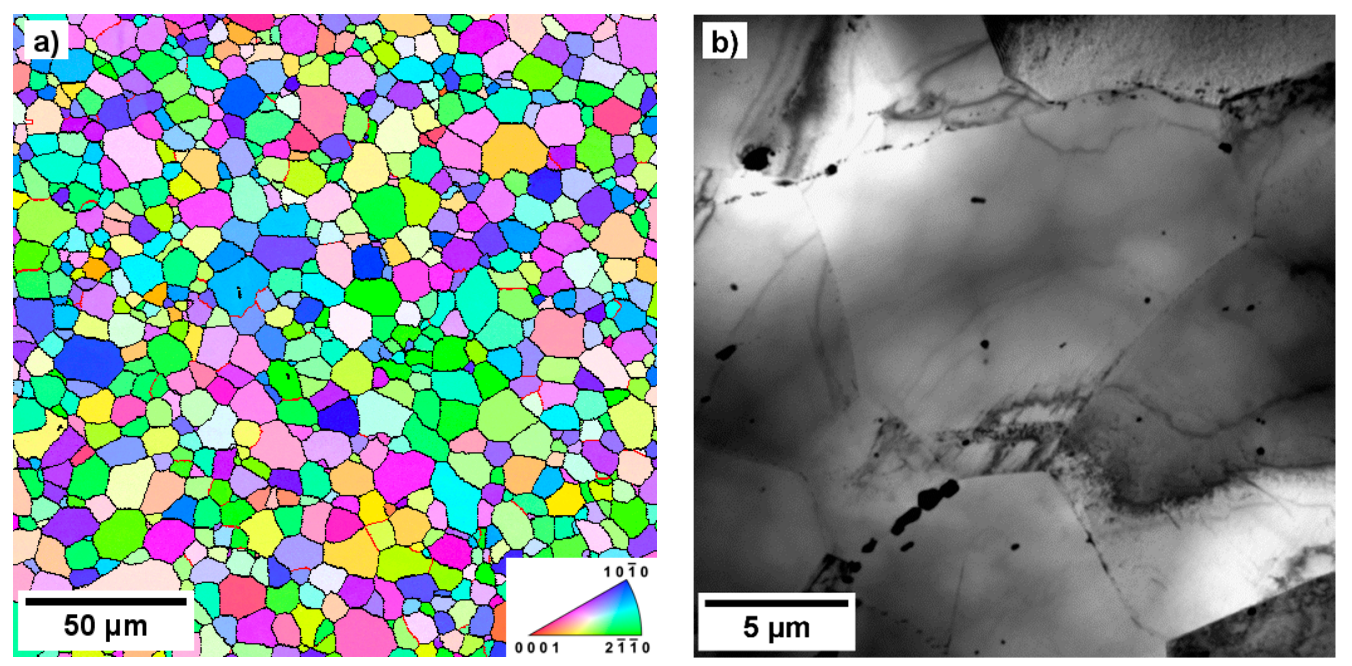

Figure 2. (a) Electron backscattered diffraction (EBSD) orientation map and (b) transmission electron microscopy (TEM) micrograph of the as-extruded (EX) sample (cross-section).



Figure 3. X-ray diffractometer (XRD) pole figures of the EX sample (cross-section).

\subsection{Microstructure after ECAP}

Significant grain refinement was observed in specimens processed by an increasing number of ECAP passes. The corresponding EBSD orientation maps of $1 \mathrm{P}, 4 \mathrm{P}$, and $8 \mathrm{P}$ samples are shown in Figure $4 \mathrm{a}-\mathrm{C}$, respectively. As is typical for many other $\mathrm{Mg}$ alloys, the first pass resulted in the formation 
of a non-homogeneous microstructure. Grain refinement occurred particularly along the former grain boundaries, and large grains were heavily deformed, as manifested by the variation of colors in individual grains. The large grains of up to $20 \mu \mathrm{m}$ in diameter were surrounded by small grains with a size of $3 \mu \mathrm{m}$. Increasing strain imposed on the material by successive ECAP passes resulted in the higher degree of refinement, and ultimately in the homogenization of the microstructure. The average grain size determined in the $4 \mathrm{P}$ and $8 \mathrm{P}$ samples was $\sim 2.6$ and $\sim 1.5 \mu \mathrm{m}$, respectively.

Figure 5 shows the pole figure measured in the $8 \mathrm{P}$ sample. The texture exhibits the typical basal slip component, which corresponds to grains with c-axes tilted by $45^{\circ}$ from the ED. However, a significant volume fraction of grains was oriented with the c-axis perpendicular to the processing direction. As a result, the basal slip texture component reached a texture strength of only $\sim 9$. Note that the texture strength of this component was found to be more than 15 in low-alloyed Mg alloys without rare earth elements $[27,28]$.
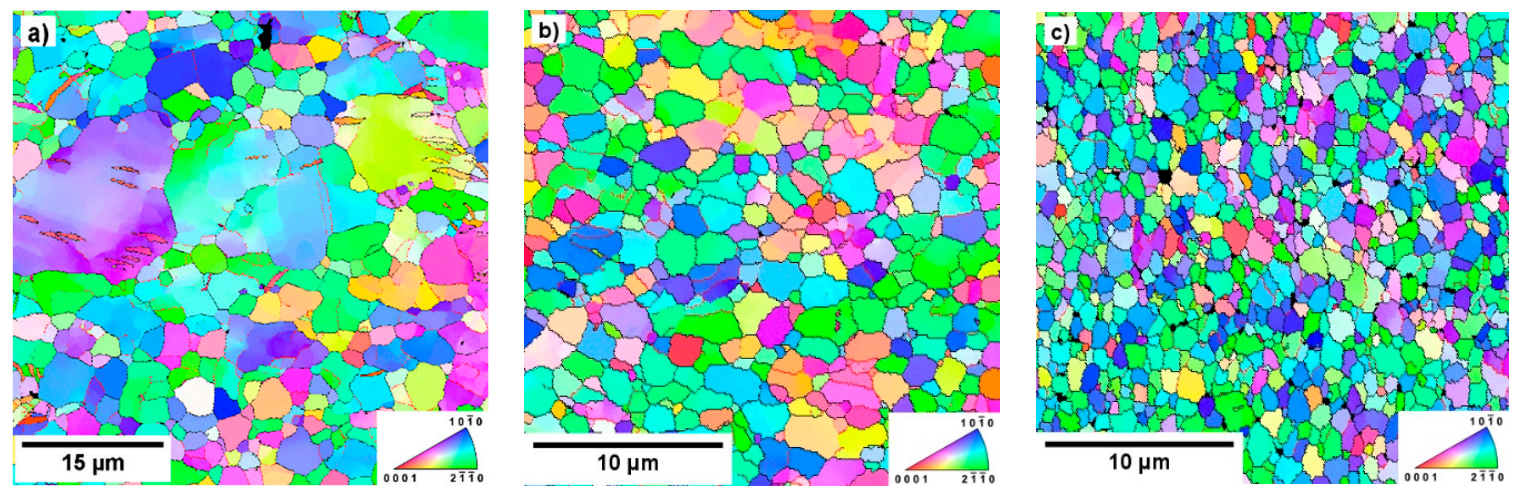

Figure 4. EBSD orientation maps of (a) 1P sample, (b) 4P sample, and (c) 8P sample (cross-section).

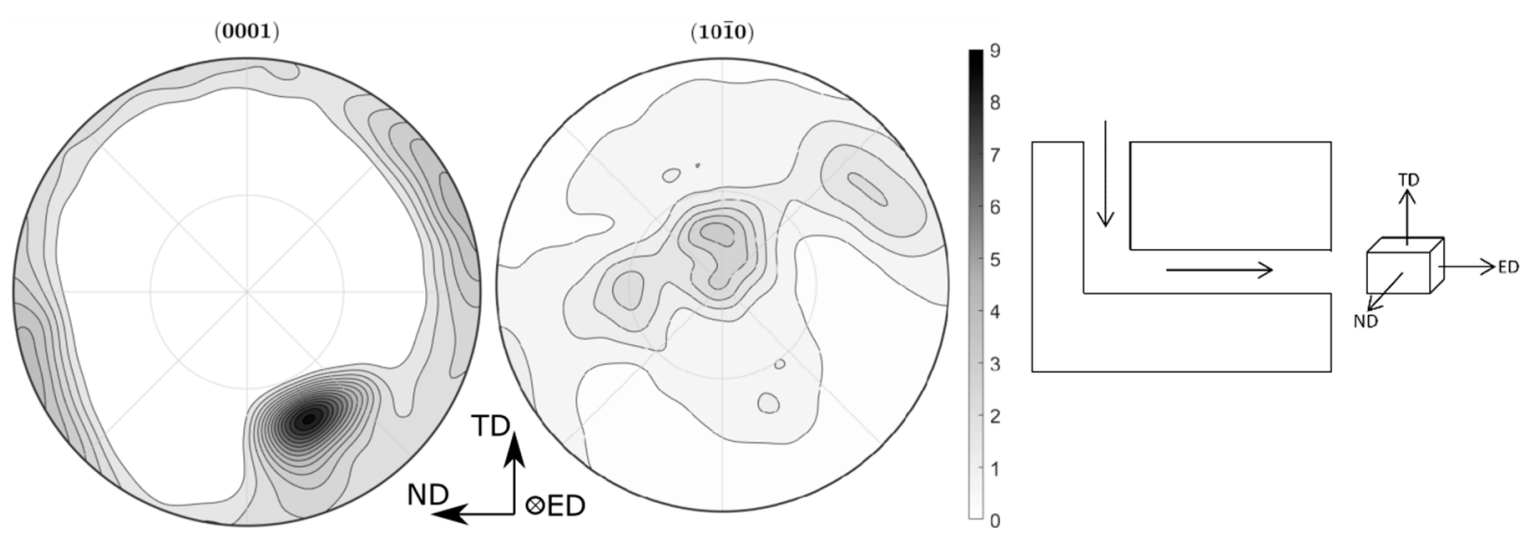

Figure 5. EBSD pole figure of the 8P sample (cross-section).

TEM investigation of the microstructure of specimens after different numbers of ECAP passes is consistent with the grain refinement observed by EBSD (compare Figures 6 and 7 with Figure 4a-c). In contrast to the as-extruded condition, the distribution of secondary phase particles in the ECAPed specimens was rather homogeneous, that is, they are distributed both along grain boundaries as well as in grain interiors. The size of the particles did not significantly change during the ECAP straining. Interestingly, significant residual strain was observed in the 8P sample (see Figure 7a). Moreover, higher magnification shows that the magnesium matrix contains also a large number of tiny secondary phase precipitates (see Figure $7 \mathrm{~b}$ ). They were identified as ordered Guinier-Preston (GP) zones (hcp, $a=0.556 \mathrm{~nm}$, monolayer $(0001)_{\alpha}$ disc) and their presence has already been reported elsewhere [7]. It should be noted, however, that these GP zones were not observed in all grains of the 8P sample. 

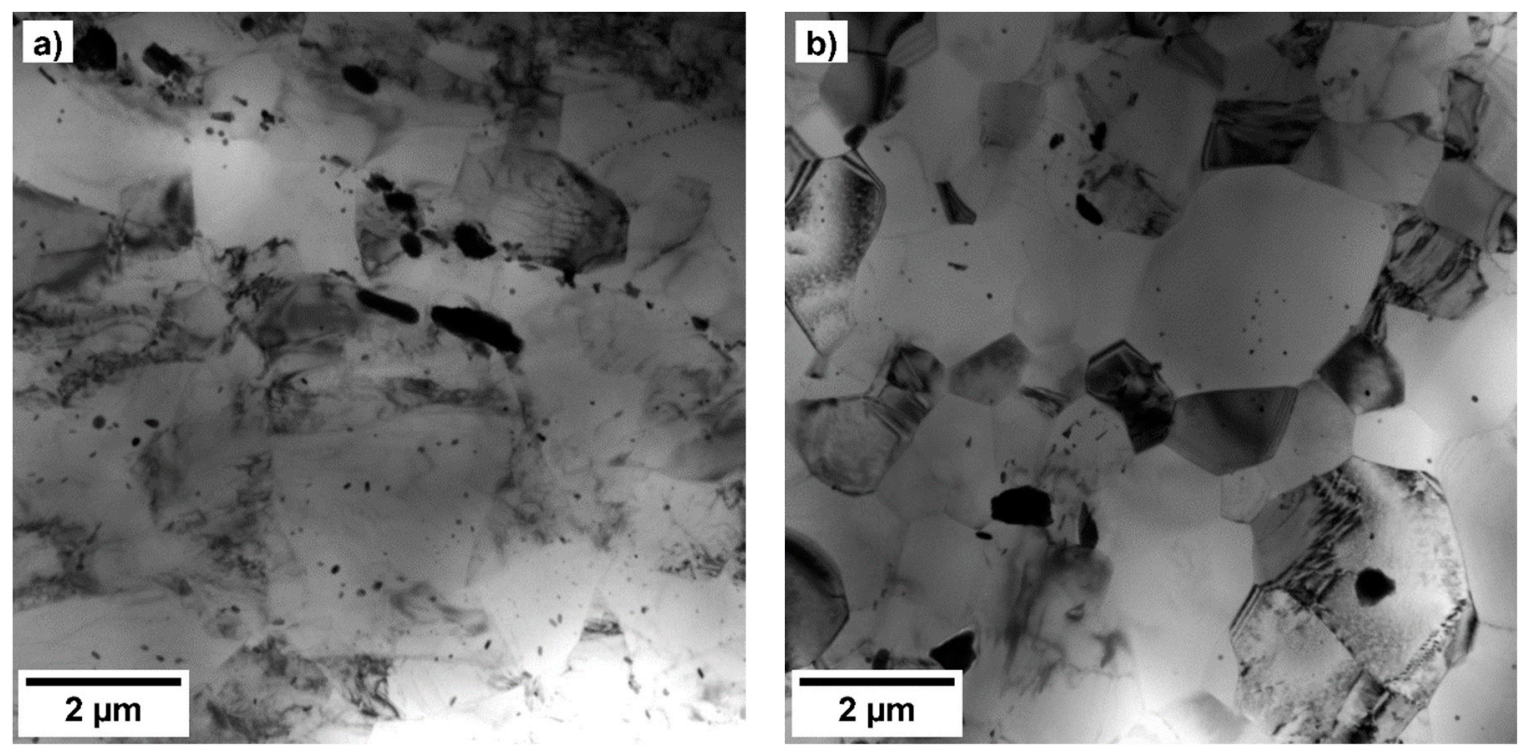

Figure 6. TEM images of (a) 1P sample and (b) 4P sample.
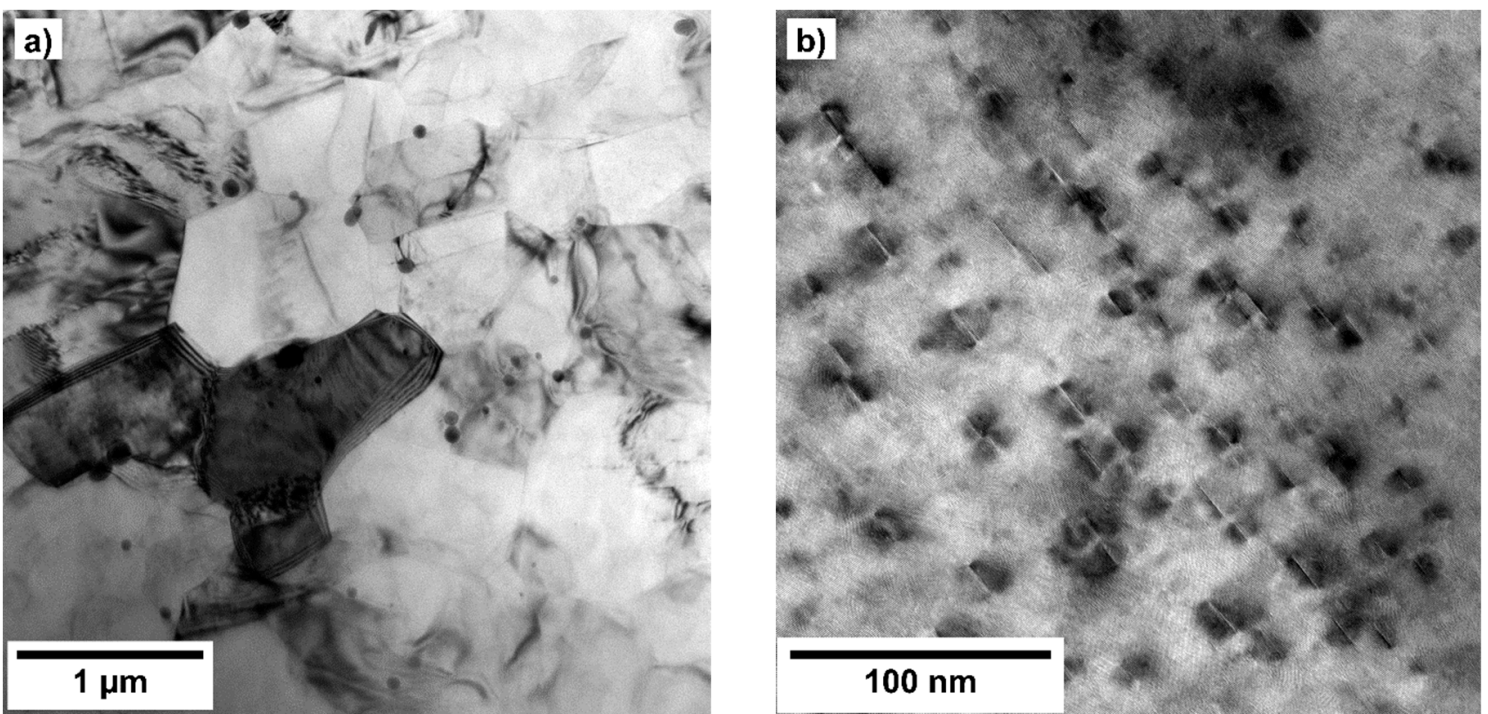

Figure 7. TEM images of (a) 8P sample and (b) detail of ordered Guinier-Preston zones.

\subsection{Mechanical Properties}

A significant change in the microstructure after ECAP alters the mechanical strength of the investigated material. In this report, we investigated microhardness as a multiaxial loading as well as compression/tensile tests as a uniaxial loading.

The resulting microhardness measurements shown in Table 2 reveal that the mechanical strength increased with the increasing number of ECAP passes, and in the final condition (8P), the microhardness was 1.5 times higher than in the as-extruded condition. Additionally, the yield compression strength (YCS) determined from flow curves (shown in Figure 8a) increased more rapidly (see Table 2). The YCS of the $8 \mathrm{P}$ sample was roughly 2.4 times higher than in the case of the as-extruded condition. The differences in the microhardness evolution and the evolution in ultimate tensile strength in uniaxial loading are usually caused by the changes in texture. The flow curves of all samples deformed in compression exhibited an S-shape character, which indicates the activation of twinning [29]. Moreover, the sharp yield point was observed in the $8 \mathrm{P}$ sample, which is quite unusual in magnesium-based materials. In order to reveal the possible effect of texture, compression tests in two mutually perpendicular directions (ED, transverse direction (TD)) were performed, and a tension test was performed along the 
processing direction (ED). The resulting flow curves are shown in Figure 8b. The tensile curve did not exhibit the S-shape character, suggesting that twinning does not occur in tension in the processing direction (ED). However, the strain anisotropy was very low despite the different characters of the flow curves.

Note that unlike ED flow curves, the flow curves along TD and normal direction (ND) did not exhibit the sharp yield point. In order to reveal the microstructural changes that led to the appearance of the sharp yield point, EBSD was performed on a sample deformed to $4 \%$ of plastic deformation along its ED. The resulting EBSD parent matrix/twin map is shown in Figure 9. The microstructure is heavily twinned, and the twinned grains are aligned in stripes declined by $\sim 45^{\circ}$ from the loading ED.

Table 2. Results of mechanical tests.

\begin{tabular}{cccc}
\hline Sample & $\begin{array}{c}\text { Microhardness } \\
(\mathbf{H V})\end{array}$ & $\begin{array}{c}\text { Yield (Compression) Strength (YCS) } \\
\mathbf{( M P a )}\end{array}$ & $\sigma_{\max } \mathbf{( M P a )}$ \\
\hline ZN11 & $48 \pm 1$ & $96 \pm 5$ & $268 \pm 9$ \\
EX & $52 \pm 1$ & $117 \pm 6$ & $322 \pm 16$ \\
\hline ZN11 1P & $63 \pm 1$ & $201 \pm 8$ & $348 \pm 28$ \\
ZN11 4P & $75 \pm 2$ & $230 \pm 15$ (compression) & $377 \pm 22($ compression) \\
ZN11 8P & $218 \pm 14$ (tension) & $335 \pm 20$ (tension) \\
\hline
\end{tabular}
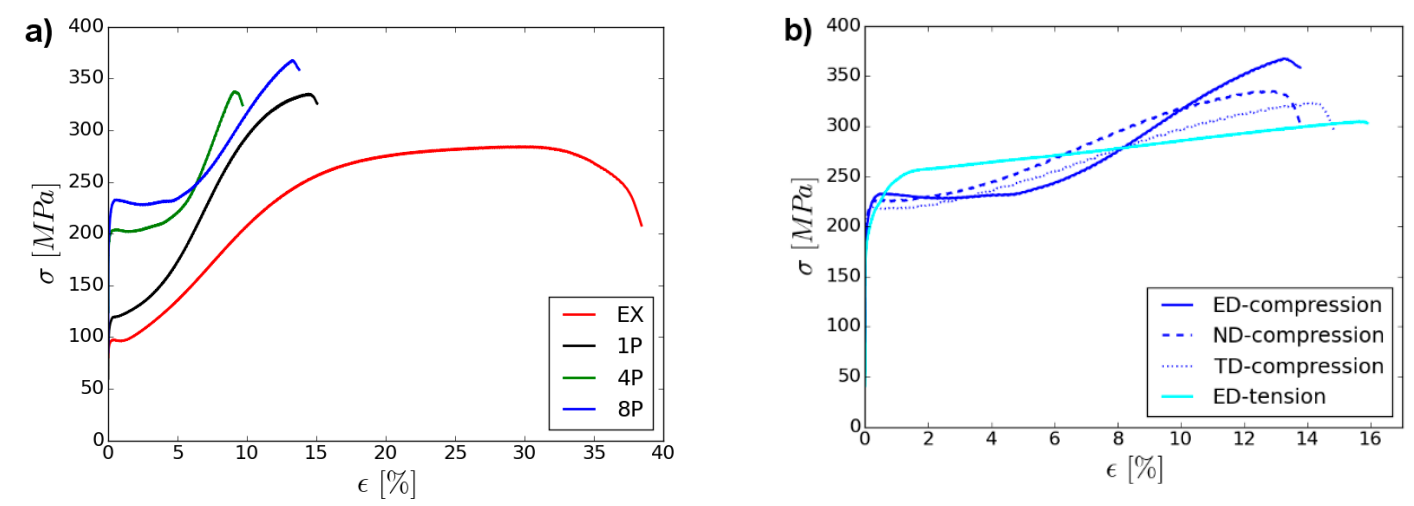

Figure 8. True stress-true strain compression curves of (a) all investigated conditions measured along the processing direction (extrusion direction (ED)) and (b) of the 8P sample measured in ED, normal direction (ND), and transverse direction (TD), see Figure 1.

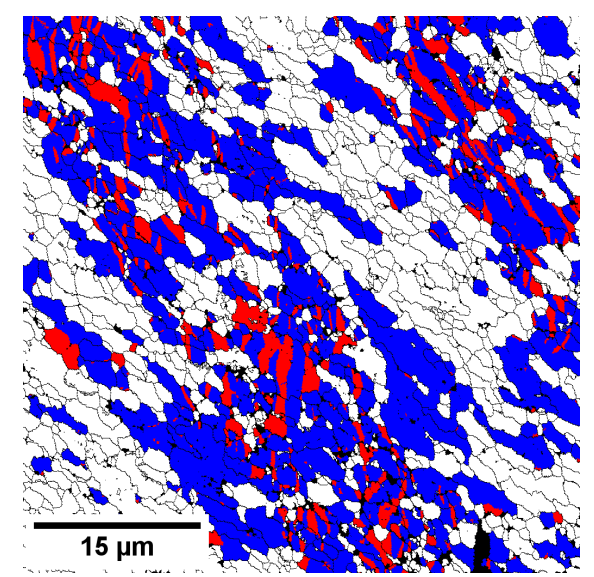

Figure 9. Parent/twin map calculated from EBSD, measured on a longitudinal section of the 8P sample, deformed in compression up to $4 \%$ of plastic deformation. Loading direction is horizontal. (Blue color corresponds to parent grains, red color corresponds to twins.) 


\section{Discussion}

The as-extruded condition exhibited a fully recrystallized and homogeneous microstructure with relatively small grains and weak texture. Comparable texture was previously observed in the same alloy [30] and also in the binary $\mathrm{Mg}-\mathrm{Nd}$ alloy [31], and is directly connected with the presence of the rare earth elements in the material. TEM investigation revealed that the secondary phase particles are mainly formed along the grain boundaries and belong to the stable $\gamma$-phase. Their inhomogeneous distribution probably resulted from the slow cooling rate after the extrusion.

Processing by ECAP resulted in additional grain refinement. Homogeneous microstructures with an average grain size of $1.5 \mu \mathrm{m}$ were achieved after eight passes of the ECAP, which is common for similarly processed magnesium alloys [27,28,32-35]. However, the studied ZN11 alloy showed enhanced strength despite the comparable grain refinement. As mentioned above, the measured increase in microhardness was by a factor of 1.5, while YCS increased by a factor of 2.5. A larger relative effect on yield stress than on microhardness is rather common; however, note that the initial material has a different grain structure in different studies $[27,28,32,36]$. Therefore, the effect of the processing on the enhanced microhardness can be analyzed with the use of the Hall-Petch (HP) plot shown in Figure 10.

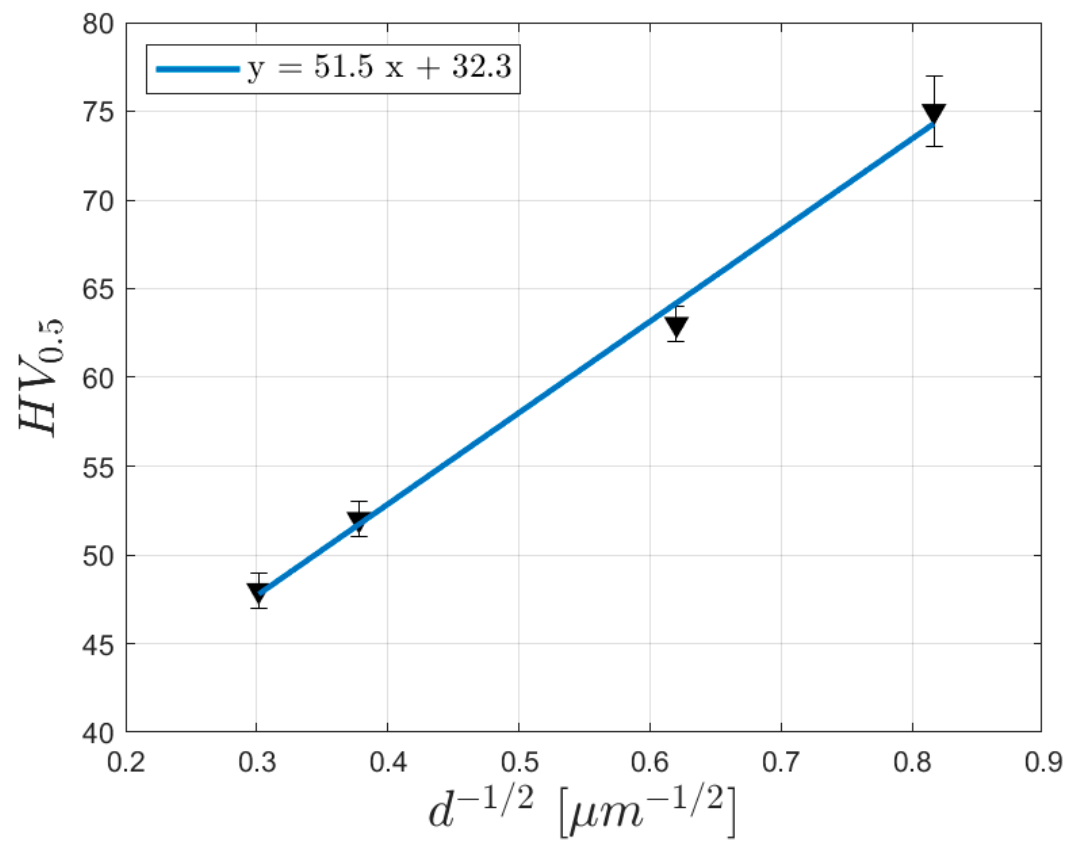

Figure 10. Hall-Petch plot showing the dependence of the microhardness on (grain size) $)^{-1 / 2}$. (Grain size was calculated from the average density of grain boundaries in the case of bimodal grain size distribution.)

The HP plot has a linear character, which indicates the grain boundary validity of the Hall-Petch relation for the studied processed samples. However, the HP slope coefficient calculated from Figure 10 was $\sim 50 \mathrm{HV} . \mu \mathrm{m}^{1 / 2}$, which is a higher value than in the $\mathrm{Mg}-\mathrm{Al}-\mathrm{Zn}$ - and $\mathrm{Mg}-\mathrm{Al}-\mathrm{RE}-$ based alloys processed similarly [28,37]. Due to lower alloying, the studied alloy has lower microhardness in its coarse-grained condition, and the effect of grain refinement is enhanced. Additionally, other strengthening mechanisms may act concurrently with the grain refinement. For instance, dislocation density observed in the $8 \mathrm{P}$ sample was significant, contrary to the previously studied alloys in [28,37]. Furthermore, TEM analysis showed that ECAP processing of the studied alloy caused the formation of GP zones. Consequently, the higher HP coefficient can be explained by the synergic effect of these three phenomena acting together. However, the contribution of each strengthening factor cannot be differentiated from the investigated samples. 
On the other hand, the increase in YCS was significantly higher than the increase in microhardness. This discrepancy can be explained by the texture evolution after ECAP. Note that the formation of the "rare earth texture" after the extrusion causes texture softening during uniaxial deformation along the extrusion direction [30]. A high volume fraction of grains had their c-axis rotated $\sim 45^{\circ}$ from the processing direction. Therefore, the activation of a basal slip system during uniaxial deformation along the extrusion direction is significantly facilitated. Figure 11a,b shows calculated distributions of the Schmid factor (SF) for all major deformation mechanisms for both extrusion and 8P conditions, when loaded in compression along the processing direction. The calculation was performed in MTEX software from raw EBSD data [23]. The SF for each point and each deformation mode was calculated and the resulting histograms were plotted.

A relatively sharp distribution of the SF for basal slip, with a maximum at SF $=0.5$, turned to broad distribution, with maximum at SF $=0$ after ECAP. It should be stressed that this texture development in the investigated alloy is quite uncommon compared to other $\mathrm{Mg}$ alloys. Usually, the initial as-extruded condition has a sharp (10̄10) fiber texture, causing low values of SF for basal slip but high values of SF for twinning. ECAP processing results in the formation of a sharp and strong basal slip texture component, representing grains having their c-axis rotated by $\sim 45^{\circ}$ from all major axes. Consequently, significant texture softening occurs, which usually overwhelms grain boundary strengthening $[27,28]$. Therefore, the reason for the significantly higher increase of YCS as compared to HV values in the investigated alloy is the different texture evolution during ECAP. In magnesium alloys, the texture is typically formed during ECAP by the pronounced activation of a basal slip, or by combined activation of basal and non-basal slip systems [28,32]. The texture development in the investigated alloy can be explained according to the recently reported model on a ZN12 alloy. It was shown that a prismatic slip system has a relatively high activity during the hot rolling of the ZN12 alloy, and its effect on the texture is maintained by retarded recrystallization kinetics [38]. High activity of prismatic slip systems during ECAP causes a rotation of grains with their c-axis perpendicular to the processing direction (for details, see [28], for example). Consequently, significant grain boundary strengthening is even more promoted by the texture strengthening resulting from the processing.

However, a high volume fraction of grains having their c-axis perpendicular to the processing direction is favorable for the activation of tensile twinning during compression along the processing direction. This is also clearly visible in Figure 11b, where the distribution of the SF for tensile twinning is shown as well. High activity of twinning during the compression test also explains the formation of the sharp yield point in the ED-curve. It was shown previously that the formation of twin bands in the microstructure (Figure 9) can cause a drop in stress [39]. In order to compare changes in the deformation direction with the calculated SF for twinning, see Figures 11 and 12, which prove unambiguously that the probability of activation twinning in tension is significantly inferior to that in compression.

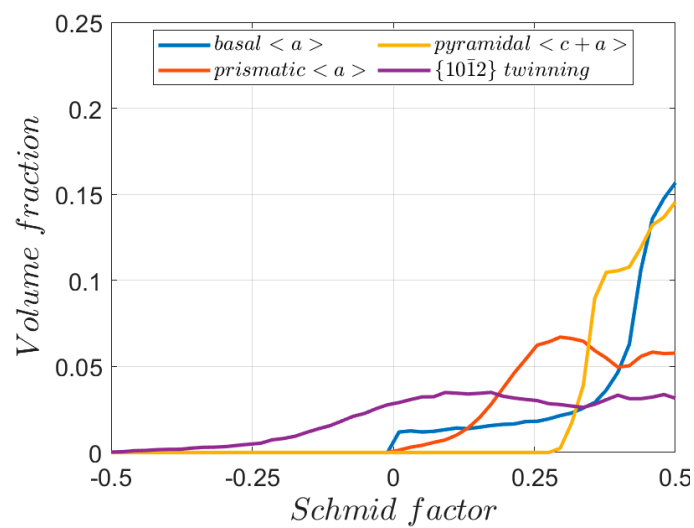

(a)

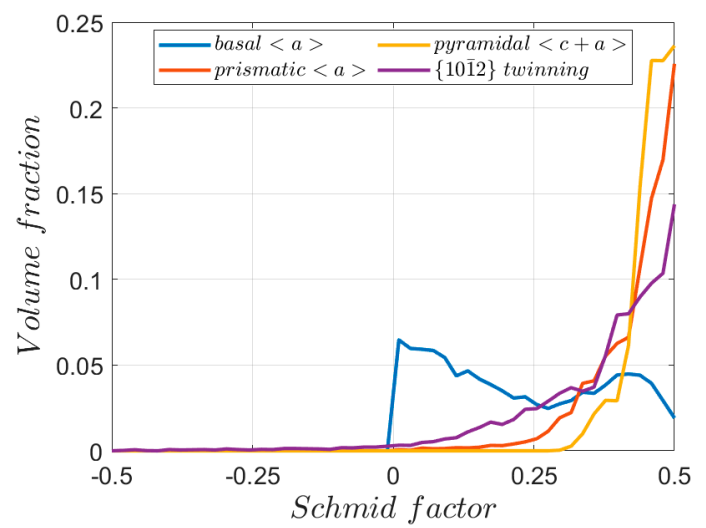

(b)

Figure 11. Schmid factor (SF) distribution calculated for major deformation mechanisms during the compression loading along the ED of (a) as-extruded sample (EX) and (b) 8P sample. 


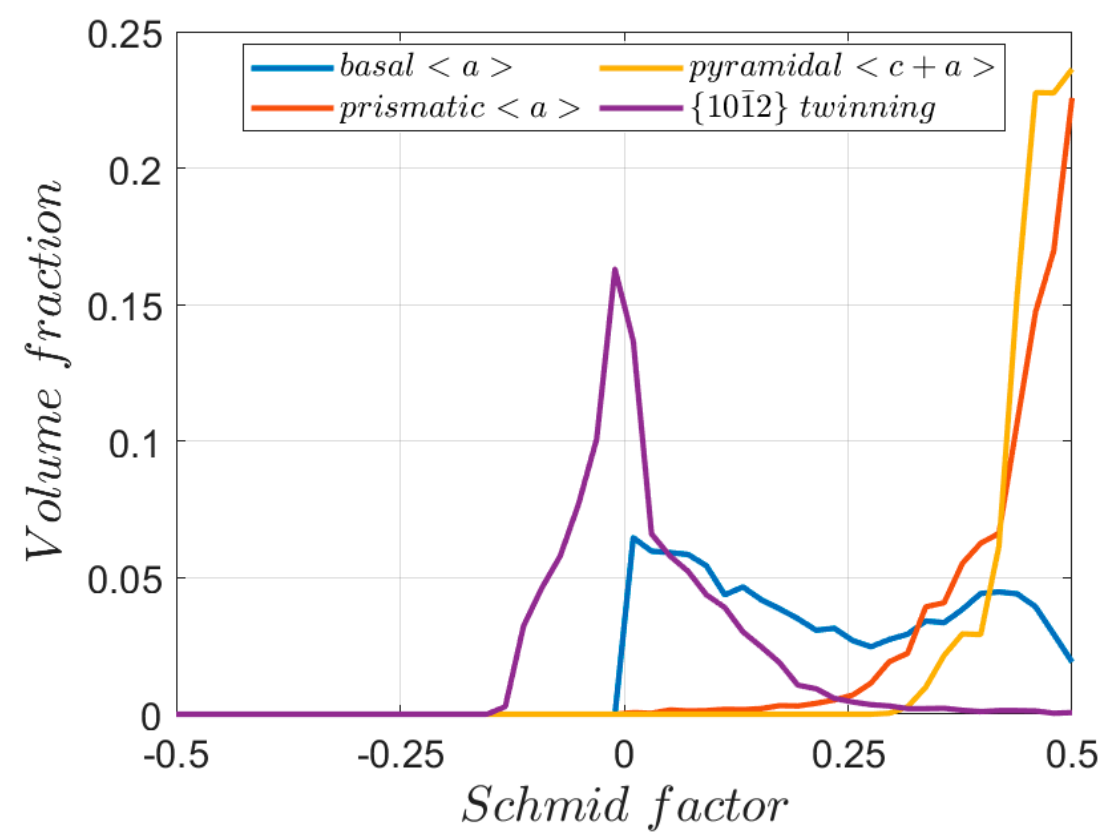

Figure 12. Schmid factor distribution calculated for major deformation mechanisms during the tensile loading along the ED of the $8 \mathrm{P}$ sample.

\section{Conclusions}

Low-alloyed magnesium alloy ZN11 was processed by hot extrusion and ECAP. The microstructure, texture, and mechanical properties were studied in detail and the main results can be summarized as follows:

The microstructure of the sample after 8 ECAP passes is fine-grained (with an average grain size of $1.5 \mu \mathrm{m}$ ) and contains significant residual strain and a large number of tiny secondary phase precipitates, which were identified as ordered Guinier-Preston zones.

The mechanical strength increased with an increasing number of ECAP passes. In the specimen after 8 ECAP passes, the microhardness was 1.5 times higher than that of the as-extruded condition. However, the yield compression strength (YCS) increased more rapidly. The YCS of the 8P sample was roughly 2.4 times higher than that of the as-extruded condition.

The effect of texture on deformation mechanisms was studied and Schmid factors were calculated. Measurements and calculations exposed the significant activity of tensile twinning $\{10 \overline{1} 2\}$ during compression loading in the ED, whereas work-hardening predominantly mediated by slip activity was observed during tensile loading in the extrusion direction.

Author Contributions: Conceptualization and methodology, J.S. and P.M.; investigation, P.M., S.Š. and J.V.; resources, J.B. and R.K.; writing-original draft preparation, J.S. and P.M.; visualization, P.M. and S.Š.; project administration, J.S. and J.K. All authors have read and agreed to the published version of the manuscript.

Funding: This research was funded by GACR project number 19-08937S. P.M. acknowledges partial financial support by ERDF under project No. CZ.02.1.01/0.0/0.0/15 003/0000485.

Conflicts of Interest: The authors declare no conflict of interest.

\section{References}

1. Dziubińska, A.; Gontarz, A.; Dziubiński, M.; Barszcz, M. The forming of magnesium alloy forgings for aircraft and automotive applications. Adv. Sci. Technol. Res. J. 2016, 10, 158-168. [CrossRef]

2. Cáceres, C.H.; Blake, A. The Strength of Concentrated Mg-Zn Solid Solutions. Phys. Status Solidi 2002, 194, 147-158. [CrossRef] 
3. Yang, J.; Wang, J.; Wang, L.; Wu, Y.; Wang, L.; Zhang, H. Microstructure and mechanical properties of $\mathrm{Mg}-4.5 \mathrm{Zn}-x \mathrm{Nd}(x=0,1$ and 2, wt\%) alloys. Mater. Sci. Eng. A 2008, 479, 339-344. [CrossRef]

4. Lü, Y.; Wang, Q.; Zeng, X.; Ding, W.; Zhai, C.; Zhu, Y. Effects of rare earths on the microstructure, properties and fracture behavior of Mg-Al alloys. Mater. Sci. Eng. A 2000, 278, 66-76. [CrossRef]

5. Gärtnerová, V.; Trojanová, Z.; Jäger, A.; Palček, P. Deformation behaviour of Mg-0.7 wt.\% Nd alloy. J. Alloys Compd. 2004, 378, 180-183. [CrossRef]

6. Javaid, A.; Hadadzadeh, A.; Czerwinski, F. Solidification behavior of dilute Mg-Zn-Nd alloys. J. Alloys Compd. 2019, 782, 132-148. [CrossRef]

7. Nie, J.-F. Precipitation and Hardening in Magnesium Alloys. Metall. Mater. Trans. A 2012, 43, 3891-3939. [CrossRef]

8. Valiev, R.Z.; Langdon, T.G. Principles of equal-channel angular pressing as a processing tool for grain refinement. Prog. Mater. Sci. 2006, 51, 881-981. [CrossRef]

9. Mostaed, E.; Hashempour, M.; Fabrizi, A.; Dellasega, D.; Bestetti, M.; Bonollo, F.; Vedani, M. Microstructure, texture evolution, mechanical properties and corrosion behavior of ECAP processed ZK60 magnesium alloy for biodegradable applications. J. Mech. Behav. Biomed. Mater. 2014, 37, 307-322. [CrossRef]

10. Minárik, P.; Veselý, J.; Král, R.; Bohlen, J.; Kubásek, J.; Janeček, M.; Stráská, J. Exceptional mechanical properties of ultra-fine grain Mg-4Y-3RE alloy processed by ECAP. Mater. Sci. Eng. A 2017, 708, 193-198. [CrossRef]

11. Cabibbo, M.; Paoletti, C.; Minárik, P.; Král, R.; Zemková, M. Secondary phase precipitation and thermally stable microstructure refinement induced by ECAP on Mg-Y-Nd (WN43) alloy. Mater. Lett. 2019, 237, 5-8. [CrossRef]

12. Zhao, S.; Guo, E.; Cao, G.; Wang, L.; Lun, Y.; Feng, Y. Microstructure and mechanical properties of $\mathrm{Mg}-\mathrm{Nd}-\mathrm{Zn}-\mathrm{Zr}$ alloy processed by integrated extrusion and equal channel angular pressing. J. Alloys Compd. 2017, 705, 118-125. [CrossRef]

13. Zhang, W.; Tan, L.; Ni, D.; Chen, J.; Zhao, Y.-C.; Liu, L.; Shuai, C.; Yang, K.; Atrens, A.; Zhao, M.-C. Effect of grain refinement and crystallographic texture produced by friction stir processing on the biodegradation behavior of a Mg-Nd-Zn alloy. J. Mater. Sci. Technol. 2019, 35, 777-783. [CrossRef]

14. Dvorský, D.; Kubásek, J.; Vojtěch, D.; Voňavková, I.; Veselý, M.; Čavojský, M. Structure and mechanical characterization of Mg-Nd-Zn alloys prepared by different processes. IOP Conf. Ser. Mater. Sci. Eng. 2017, 179, 012018. [CrossRef]

15. Nakashima, K.; Horita, Z.; Nemoto, M.; Langdon, T.G. Development of a multi-pass facility for equal-channel angular pressing to high total strains. Mater. Sci. Eng. A 2000, 281, 82-87. [CrossRef]

16. Krajňák, T.; Minárik, P.; Stráská, J.; Gubicza, J.; Máthis, K.; Janeček, M. Influence of equal channel angular pressing temperature on texture, microstructure and mechanical properties of extruded AX41 magnesium. J. Alloys Compd. 2017, 705, 273-282. [CrossRef]

17. Shin, D.H.; Pak, J.-J.; Kim, Y.K.; Park, K.-T.; Kim, Y.-S. Effect of pressing temperature on microstructure and tensile behavior of low carbon steels processed by equal channel angular pressing. Mater. Sci. Eng. A 2002, 323, 409-415. [CrossRef]

18. Chen, Y.C.; Huang, Y.Y.; Chang, C.P.; Kao, P.W. The effect of extrusion temperature on the development of deformation microstructures in 5052 aluminium alloy processed by equal channel angular extrusion. Acta Mater. 2003, 51, 2005-2015. [CrossRef]

19. Huang, W.H.; Yu, C.Y.; Kao, P.W.; Chang, C.P. The effect of strain path and temperature on the microstructure developed in copper processed by ECAE. Mater. Sci. Eng. A 2004, 366, 221-228. [CrossRef]

20. Málek, P.; Cieslar, M.; Islamgaliev, R.K. The influence of ECAP temperature on the stability of $\mathrm{Al}-\mathrm{Zn}-\mathrm{Mg}-\mathrm{Cu}$ alloy. J. Alloys Compd. 2004, 378, 237-241. [CrossRef]

21. Goloborodko, A.; Sitdikov, O.; Kaibyshev, R.; Miura, H.; Sakai, T. Effect of pressing temperature on fine-grained structure formation in 7475 aluminum alloy during ECAP. Mater. Sci. Eng. A 2004, 381, 121-128. [CrossRef]

22. Wang, Y.Y.; Sun, P.L.; Kao, P.W.; Chang, C.P. Effect of deformation temperature on the microstructure developed in commercial purity aluminum processed by equal channel angular extrusion. Scr. Mater. 2004, 50, 613-617. [CrossRef]

23. Bachmann, F.; Hielscher, R.; Schaeben, H. Texture Analysis with MTEX-Free and Open Source Software Toolbox. Solid State Phenom. 2010, 160, 63-68. [CrossRef] 
24. Gottstein, G. Physical Foundations of Materials Science; Springer: Berlin/Heidelberg, Germany, 2004; ISBN 978-3-540-40139-1.

25. Mayama, T.; Noda, M.; Chiba, R.; Kuroda, M. Crystal plasticity analysis of texture development in magnesium alloy during extrusion. Int. J. Plast. 2011, 27, 1916-1935. [CrossRef]

26. Stanford, N.; Barnett, M.R. The origin of "rare earth" texture development in extruded Mg-based alloys and its effect on tensile ductility. Mater. Sci. Eng. A 2008, 496, 399-408. [CrossRef]

27. Janeček, M.; Yi, S.; Král, R.; Vrátná, J.; Kainer, K.U. Texture and microstructure evolution in ultrafine-grained AZ31 processed by EX-ECAP. J. Mater. Sci. 2010, 45, 4665-4671. [CrossRef]

28. Minárik, P.; Král, R.; Čížek, J.; Chmelík, F. Effect of different c/a ratio on the microstructure and mechanical properties in magnesium alloys processed by ECAP. Acta Mater. 2016, 107, 83-95. [CrossRef]

29. Dobroň, P.; Chmelík, F.; Yi, S.; Parfenenko, K.; Letzig, D.; Bohlen, J. Grain size effects on deformation twinning in an extruded magnesium alloy tested in compression. Scr. Mater. 2011, 65, 424-427. [CrossRef]

30. Nascimento, L.; Yi, S.; Bohlen, J.; Fuskova, L.; Letzig, D.; Kainer, K.U. High cycle fatigue behaviour of magnesium alloys. Procedia Eng. 2010, 2, 743-750. [CrossRef]

31. Minárik, P.; Drozdenko, D.; Zemková, M.; Veselý, J.; Čapek, J.; Bohlen, J.; Dobroň, P. Advanced analysis of the deformation mechanisms in extruded magnesium alloys containing neodymium or yttrium. Mater. Sci. Eng. A 2019, 759, 455-464. [CrossRef]

32. Krajňák, T.; Minárik, P.; Gubicza, J.; Máthis, K.; Kužel, R.; Janeček, M. Influence of equal channel angular pressing routes on texture, microstructure and mechanical properties of extruded AX41 magnesium alloy. Mater. Charact. 2017, 123, 282-293. [CrossRef]

33. Figueiredo, R.B.; Langdon, T.G. Factors influencing superplastic behavior in a magnesium ZK60 alloy processed by equal-channel angular pressing. Mater. Sci. Eng. A 2009, 503, 141-144. [CrossRef]

34. Kang, Z.; Zhou, L.; Zhang, J. Achieving high strain rate superplasticity in Mg-Y-Nd-Zr alloy processed by homogenization treatment and equal channel angular pressing. Mater. Sci. Eng. A 2015, 633, 59-62. [CrossRef]

35. Figueiredo, R.B.; Langdon, T.G. Grain refinement and mechanical behavior of a magnesium alloy processed by ECAP. J. Mater. Sci. 2010, 45, 4827-4836. [CrossRef]

36. Krajňák, T.; Minárik, P.; Stráská, J.; Gubicza, J.; Máthis, K.; Janeček, M. Influence of the initial state on the microstructure and mechanical properties of AX41 alloy processed by ECAP. J. Mater. Sci. 2019, 54, 3469-3484. [CrossRef]

37. Stráská, J.; Janeček, M.; Čížek, J.; Stráský, J.; Hadzima, B. Microstructure stability of ultra-fine grained magnesium alloy AZ31 processed by extrusion and equal-channel angular pressing (EX-ECAP). Mater. Charact. 2014, 94, 69-79. [CrossRef]

38. Zeng, X.; Minárik, P.; Dobroň, P.; Letzig, D.; Kainer, K.U.; Yi, S. Role of deformation mechanisms and grain growth in microstructure evolution during recrystallization of Mg-Nd based alloys. Scr. Mater. 2019, 166, 53-57. [CrossRef]

39. Hazeli, K.; Cuadra, J.; Vanniamparambil, P.A.; Kontsos, A. In situ identification of twin-related bands near yielding in a magnesium alloy. Scr. Mater. 2013, 68, 83-86. [CrossRef]

(C) 2019 by the authors. Licensee MDPI, Basel, Switzerland. This article is an open access article distributed under the terms and conditions of the Creative Commons Attribution (CC BY) license (http://creativecommons.org/licenses/by/4.0/). 